\title{
Minimizing the Carbon Footprint of Material Handling Equipment: Comparison of Electric and LPG Forklifts
}

\author{
Francesco Facchini(D), Giovanni Mummolo(D), Giorgio Mossa (D), Salvatore Digiesi(i), \\ Francesco Boenzi (iD, Rossella Verriello \\ Politecnico di Bari - Department of Mechanical, Mathematical and Management (Italy) \\ francesco.faccbini@poliba.it, giovanni.mummolo@poliba.it,giorgio.mossa@poliba.it, salvatore.digiesi@poliba.it, \\ francesco.boenzi@poliba.it, rossella.verriello@poliba.it
}

Received: July 2016

Accepted: October 2016

\section{Abstract:}

Purpose: The aim of this study is to identify the best Material Handling Equipment (MHE) to minimize the carbon footprint of inbound logistic activities, based on the type of the warehouse (layout, facilities and order-picking strategy) as well as the weight of the loads to be handled.

Design/methodology/approach: A model to select the best environmental MHE for inbound logistic activities has been developed. Environmental performance of the MHE has been evaluated in terms of carbon Footprint (CF). The model is tested with a tool adopting a VBA macro as well as a simulation software allowing the evaluation of energy and time required by the forklift in each phase of the material handling cycle: picking, sorting and storing of the items.

Findings: Nowadays, it is not possible to identify 'a priori' a particular engine equipped forklift performing better than others under an environmental perspective. Consistently, the application of the developed model allows to identify the best MHE tailored to each case analyzed.

Originality/value: This work gives a contribution to the disagreement between environmental performances of forklifts equipped with different engines. The developed model can be considered a valid support for decision makers to identify the best MHE minimizing the carbon footprint of inbound logistic activities. 
Keywords: sustainable logistic, carbon footprint, material handling equipment, green warehousing

\section{Introduction}

In the last decade, the average annual increase of $\mathrm{CO}_{2}$ emissions was about 3\%. In 2014 the value of $\mathrm{CO}_{2}$ emitted in the world reached the new record of 35.7 billion tonnes (Olivier \& Muntean, 2015). Taking into account all Greenhouse Gases (GHGs), equivalent carbon dioxide $\left(\mathrm{CO}_{2 \mathrm{eq}}\right)$ emissions reached a total amount of about 50 billion tonnes in the year 2014, and are forecasted to rise to 58 billion tonnes of $\mathrm{CO}_{2 \text { eq }}$ in 2020 (Fichtinger, Ries, Grosse \& Baker, 2015). With reference to the logistics and transport sector, the emissions generated by the related consumption of energy account for about 2.8 billion tonnes of $\mathrm{CO}_{2 \mathrm{eq}}$ and represent about 5.5\% of the total GHGs emissions (Fichtinger et al., 2015). Therefore, the environmentally sustainable management of logistic activities became an essential element of business strategy and competitive advantage (Dey, LaGuardia \& Srinivasan, 2011). Strong pressure exerted by mass media and European legislation imposed multiple new challenges to business organizations in terms of better working conditions, workers' safety and reduction in carbon footprint.

In recent years, most of the research concerning environmental impact of logistics focused on the GHGs emissions associated with transport activities. There is a growing body of literature focusing on inventory management policies. The internalization of the cost of externalities gives rise to new logistic cost estimates (Digiesi, Mascolo, Mossa \& Mummolo, 2016). Research by Boenzi, Digiesi, Facchini and Mummolo (2015) showed that the environmental performance, evaluated as external costs, of the inbound logistic activities is strongly related to the storage configuration and to the order picking strategy.

Environmental impact due to material handling, storage, and picking operations is a substantially unexplored field of research. In Amjed and Harrison (2013), a warehouse shows eight potential major research areas which are: warehouse facility design, warehouse layout, inventory management, Mechanical Handling Equipment (MHE), warehouse staff, warehouse operations, onsite facilities and Warehouse Management System (WMS). According to Amjed and Harrison (2013), each area of research is able to ensure a significant contribution for logistic sustainability improvement. As far as the MHE area is concerned, in order to minimize emissions due to order picking activities, a fundamental role is played by the optimal equipment selection.

The paper focuses on forklift selection in case warehouse layout and its capacity, as well as size and weight of the stored items are given. 
According to Johnson (2008) 'the carbon footprints of electric and LPG fork-lifts are, in principle, about equal, while in actual practice, LPG footprint is smaller than that of electricity'. On the other hand, Toyota (2002) claims that the carbon footprint of a LPG forklift is about twice that of an electric forklift. Therefore the question is: 'what is the forklift engine, available on the market that ensures the minimal carbon footprint for the inbound material handling activities?'

In order to answer to the question, this paper proposes to integrate a carbon footprint calculator with a simulation-based model.

The paper is organized as follows: in Section 2, scope and methodology of the model are presented; in Section 3 and 4, the model is applied to different cases and results obtained are presented and discussed; finally, in Section 5, conclusions are detailed.

\section{Scope and Methodology}

The main object is to identify the best environmental MHE for inbound logistic activities. Consistently, a model to select the MHE with the lowest impact in terms of Carbon Footprint (CF) has been developed. Two main classes of MHE have been considered in the model: forklifts powered by fossil fuel and by electricity. Basically, the CF of inbound logistic activities depends on forklift energy consumption and on the time required to complete a process. The material handling process considered in the model consists of three main steps:

1. the unloaded forklift leaves the loading/unloading area $\left(\mathrm{A}_{\mathrm{LU}}\right)$ of the warehouse and reaches the storage area (SA) whose access point is located in the middle of front side; a constant carrying speed has been assumed;

2. the forklift stops at SA and picks the number of items in order to both maximize the utilization ratio and to minimize the number of movements and travels required. A special equipment is adopted in order to saturate available capacity of the forklift ensuring the safe loading.

3. the loaded forklift leaves the SA and reaches the loading/unloading area $\left(\mathrm{A}_{\mathrm{LU}}\right)$ of the warehouse. In this phase, the travel speed of the forklift depends on the weight of the load carried up and on the power source of the forklift. In any case, the travel speed cannot exceed the 'safe speed' suggested by occupational safety guidelines for Powered Industrial Trucks (ANSI, 2012) consistently with the truck type, the carried load, the operating surface conditions, as well as other safety issues. 
Energy $(E)$ and time $(t)$ required by the forklift for picking $Q$ items from the warehouse are strongly related to the number and features of the items stocked in the warehouse, to the distance between $A_{\mathrm{LU}}$ and SA as well as to the loading capacity of the forklift. Consistently, the Carbon Footprint (CF) of material handling activities is evaluated by means of Equation (1) for both fuel engine equipped forklifts and electrical powered forklifts:

$$
C F=E H R \cdot t
$$

Where:

- $\quad$ EHR: Emission Hourly Rate $\left[\mathrm{kgCO}_{2} / \mathrm{h}\right]$;

- $\quad t$ : total cycle time $[\mathrm{h}]$.

The EHR can be calculated by means of Equations (2) and (3) for fuel engine equipped forklifts and for electrical powered forklifts, respectively:

$$
\begin{aligned}
& E H R_{F U E L}=F E F \cdot F C H R \\
& E H R_{E L}=\frac{1}{\eta} E E F \cdot E C H R
\end{aligned}
$$

Where:

- FEF: Fuel Emission Factor $\left[\mathrm{kgCO}_{2} / \mathrm{kWh}\right]$;

- FCHR: average Fuel Consumption Hourly Rate $[\mathrm{kWh} / \mathrm{h}]$;

- EEF: Electricity Emission Factor $\left[\mathrm{kgCO}_{2} / \mathrm{kWh}\right]$;

- ECHR: average electric Energy Consumption Hourly Rate [kWh /h];

- $\eta$ : overall efficiency of the electric energy transfer process from the production origin to the battery energy storage (product of the efficiencies of all the involved electric equipment and of the electrochemical charging efficiency of the battery);

The total time $(\mathrm{t})$ considered in the model can be defined as the product of the average cycle time $\left(\overline{\mathrm{t}}_{\mathrm{c}}\right)$ and the cycles number $(\mathbb{N})$. The average cycle time $\left(\bar{t}_{c}\right)$ consists of the roundtrip translation time and of the lift time. The cycles number $(\mathrm{N})$ represents the number of roundtrips required to complete the process. Under the hypothesis that all the items in the storage are identical (same weight $\mathrm{W}$ and dimensions) and stackable, it is possible to define the Batch Size (BS) of the forklift as the maximum number of transportable units, in order to maximize its utilization. The BS can be calculated as the lower integer of the ratio between the rated Load Capacity (LC) of the forklift and the weight (W) of an item. 
Consequently, the cycles number $(\mathrm{N})$ is calculated as the upper integer of the ratio between the storage capacity (Q) and the batch size (BS). The total time ( $t$ ) is at last expressed by Equation (4).

$$
t=2\left(\frac{d}{s_{t}}+\frac{b}{s_{l}}\right)\left[\frac{Q^{-}}{B S}\right.
$$

Where:

- $d$ : average distance travelled in a cycle $[\mathrm{m}]$;

- $s_{t}:$ average translation speed $[\mathrm{km} / \mathrm{h}]$;

- $\quad b$ : average lifting height $[\mathrm{m}]$;

- $s_{l:}$ average lift speed $[\mathrm{km} / \mathrm{h}]$;

- $\quad B S$ : forklift batch size. $B S=\left\lfloor\frac{L C}{W}\right\rfloor$ and, consistently, utilization $U=\frac{B S \cdot W}{L C}$, in which LC is the rated load capacity of the forklift truck and $\mathrm{W}$ is the weight of an item.

The average distance travelled ' $\mathrm{d}$ ' includes the distance travelled from $\mathrm{A}_{\mathrm{LU}}$ and $\mathrm{SA}$ and the distance travelled in the storage area for picking items. The latter is evaluated according to standard criteria pertaining the minimal distance traveled in condition of equiprobable access to the stocked items. Considering the front side $(\mathrm{U})$ end the depth $(\mathrm{V})$ of the $\mathrm{SA}$, the average distance travelled is $\mathrm{d}=$ $\mathrm{U} / 4+\mathrm{V} / 2$.

Introduced the subscripts also for the term $\mathrm{t}$ and for its components, the CF comparison condition to identify the best MHE is expressed by Inequality (5):

$$
E H R_{F U E L} \cdot t_{F U E L}-E H R_{E L} \cdot t_{E L}>0
$$

A difference greater than zero indicates a preference for the electric forklift. The environmental preference condition can be rewritten as in Inequality (6).

$$
\frac{E H R_{F U E L}}{E H R_{E L}}>\frac{\left(\frac{d}{s_{t E L}}+\frac{b}{s_{l \mathrm{EL}}}\right)\left[\frac{\mathscr{Q}}{B s_{E L}}\right]}{\left(\frac{d}{s_{t \mathrm{FUEL}}}+\frac{b}{s_{l \mathrm{FUEL}}}\right)\left[\frac{Q}{B s_{\text {FUEL }}}\right]}
$$

For an average travelled distance much greater than the average lifting height, the lift time for both the types of forklift can be neglected. In general, the product of the two terms $(\mathrm{h} / \mathrm{d})$ and $\left(\mathrm{s}_{\mathrm{t}} / \mathrm{s}_{\mathrm{l}}\right)$ should be evaluated for both types of forklift, but, in most practical cases, it can be assumed negligible $\left(\mathrm{h} / \mathrm{d} \mathrm{s}_{\mathrm{t}} / \mathrm{s}_{1}<<1\right)$. Under this hypothesis, the CF preference condition can be expressed as in Inequality (7), in which it is a function of the forklift utilization. 


$$
\frac{E H R_{F U E L}}{E H R_{E L}}>\frac{s_{t \mathrm{FUEL}}}{s_{t E L}} \frac{\left\lceil\frac{Q}{B S_{E L}}\right\rceil}{\left.\frac{Q}{B S_{F U E L}}\right\rceil}
$$

The model is validated by means of a tool allowing to evaluate the energy and the time required by the forklift in each phase of the material handling cycle: empty truck travel, item picking and transport, item unloading. The tool is based on a VBA macro and on the simulation software: 'FlexSim Simulator Software ${ }^{\circledR}$ - Express free version (download at: https://www.flexsim.com/free-trial/). The VBA macro gets data (times required for Material Handling Cycle) from the simulation software, and calculates the related Carbon Footprint according to (1).

The order-picking strategy considered for the warehouse management is based on a picker-to-parts system employing workers and counterbalance forklifts. In the following, the assumptions adopted are:

- No priority rules are established among items;

- number of items to be handled, within a given time horizon, is given;

- an item consists of a single product or a batch of products;

- items stocked in the warehouse are of prismatic form and are characterized by the same sizes ( $d x$, $d y$, and $d z)$ and weight $(W)$;

- stackable units storage configuration is adopted;

- items are stocked in stockpiles of same height and each stockpile does not exceed 4 [m];

- a storage configuration is univocally identified by the numbers $\left(n_{x}, n_{y}, n_{x}\right)$, of items stored along the $\mathrm{x}, \mathrm{y}$ and $\mathrm{z}$-axis, respectively.

- $\mathrm{Q}$ is the storage capacity of the warehouse: $Q=n_{x} \cdot n_{y} \cdot n_{z}$

- times of the transient phases (acceleration and deceleration of the forklift) (Chao-Hsien-Pan, Ming-Hun \& Wen-Linag, 2014) and forklift waiting times are negligible in the cycle time;

- warehouse layout is of a Rectangular type (Figure 1), with a storage area (SA) and a single loading/unloading area $\left(\mathrm{A}_{\mathrm{LU}}\right)$;

- each stockpile is accessed from a front storage area $\left(\mathrm{F}_{\mathrm{SA}}\right)$ due to limited aisles width;

- the distance between the loading/unloading area $\left(\mathrm{A}_{\mathrm{LU}}\right)$ of the warehouse and the storage area $(\mathrm{SA})$ is given. 


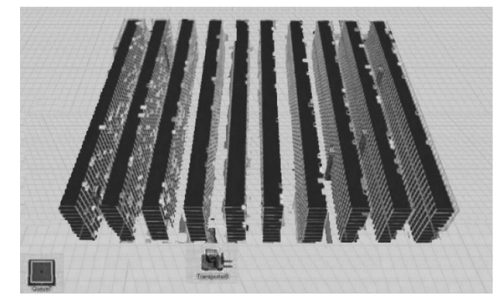

Figure 1. Layout of the warehouse (screenshot from FlexSim Simulation software $^{\circledR}$ )

\section{Numerical Simulation of Material Handling}

In order to evaluate the tool effectiveness, the model has been applied to a full scale numerical case. Two counter-balance forklifts equipped with LPG and electric engine are considered.

The data employed for the environmental preference evaluation are listed in Table 1. In detail, the data specified for the LPG powered forklift are the FEF and the FCHR for the considered truck model (Equation 2). For the electric powered forklift (Equation 3), the ECHR is specific to the truck model and the reported EEF is taken from (Eurostat, 2015). This value is derived considering the average mix of production sources of electricity in EU countries. The overall efficiency $\eta$ of electric energy storage can be assumed equal to 0.85 , considering, optimistically, 90\% energy efficiency for the battery charging process and around 95\% for all the other ancillary equipment.

\begin{tabular}{|c|c|c|c|c|}
\hline \multirow{2}{*}{ LPG powered forklift } & $\mathrm{FEF}\left[\mathrm{kgCO}_{2} / \mathrm{kWh}\right]$ & FCHR $[\mathrm{kg} / \mathrm{h}]$ & $\mathrm{LCV}[\mathrm{kWh} / \mathrm{kg}]$ & $\mathrm{EHR}\left[\mathrm{kgCO}_{2} / \mathrm{h}\right]$ \\
\hline & $0.227^{(*)}$ & $6.6^{(* *)}$ & 13.1 & 19.6 \\
\hline \multirow{2}{*}{ Electric powered forklift } & $\mathrm{E}_{\mathrm{R}}\left[\mathrm{kgCO}_{2} / \mathrm{kWh}\right]$ & ECHR [kWh /h] & $\eta$ & \multirow{2}{*}{4.84} \\
\hline & $0.388^{(+)}$ & $10.6^{(* *)}$ & 0.85 & \\
\hline
\end{tabular}

${ }^{*}$ source: (IPCC, 2006)

(*) source: Technical data sheet (Hyster H6.0-7.0FT and J4.0-5.0XN), based on the VDI 2198 cycle.

${ }^{(+)}$source: (Eurostat, 2015)

Table 1. Emission factors of fuels and consumption data of the considered forklifts (IPCC, 2006)

Forklift characteristic features like load capacity, fork height, translation maximum speed and engine power are listed in Table 2.

The stocked prismatic items are characterized by the following sizes: $d x=0.8[\mathrm{~m}], d y=1.2[\mathrm{~m}]$, and $d z=0.5$ $[\mathrm{m}]$. In the following, the plan of the simulations adopted is summarized. For each case, the model, on 
the basis of the input parameters, allowed to evaluate the CF required for material handling activities, consistently with the adopted assumptions.

\begin{tabular}{|c|r|r|r|r|r|r|}
\hline $\begin{array}{c}\text { Energy } \\
\text { source }\end{array}$ & $\begin{array}{c}\text { Load } \\
\text { capacity } \\
{[\mathrm{kg}]}\end{array}$ & $\begin{array}{c}\text { Fork } \\
\text { height } \\
{[\mathrm{mm}]}\end{array}$ & $\begin{array}{c}\text { Translation } \\
\text { speed } \\
{[\mathrm{km} / \mathrm{h}]}\end{array}$ & $\begin{array}{c}\text { Average } \\
\text { Lifting/Lowering speed } \\
{[\mathrm{km} / \mathrm{h}]}\end{array}$ & $\begin{array}{c}\text { Power } \\
{[\mathrm{kW}]}\end{array}$ & $\begin{array}{c}\text { Cost } \\
{[\mathrm{k}]}\end{array}$ \\
\hline LPG & 6000 & 3340 & 25.0 & 1.91 & 77 & $\approx 45$ \\
\hline Electric & 4000 & 3300 & 20.0 & 1.69 & 64.4 & $\approx 45$ \\
\hline
\end{tabular}

Table 2. Technical specifications of the forklifts

By varying the number (Q) and the features (size and weight) of the items to be stocked, as well as the distance between the loading/unloading area and the storage area $\left(\mathrm{A}_{\mathrm{LU}}-\mathrm{SA}\right)$, more than 600 numerical cases have been simulated. For each case considered, the model identified the MHE minimizing the CF of the material handling activities. As an example, results obtained in case of $A_{\mathrm{LU}}-\mathrm{SA}=20[\mathrm{~m}]$, three values of Q and three different items (differing by weight) are shown in Table 3.

\begin{tabular}{|c|c|c|c|c|c|}
\hline ID & Q [units] & Weight [kg/units] & $n_{x}$ [units] & $n_{y}$ [units] & $n_{z}$ [units] \\
\hline \#01 & 1500 & 2000 & 25 & 15 & 4 \\
\hline \#02 & 1500 & 3000 & 25 & 15 & 4 \\
\hline \#03 & 1500 & 3500 & 25 & 15 & 4 \\
\hline \#04 & 6500 & 2000 & 50 & 26 & 5 \\
\hline \#05 & 6500 & 3000 & 50 & 26 & 5 \\
\hline \#06 & 6500 & 3500 & 50 & 26 & 5 \\
\hline \#07 & 16000 & 2000 & 64 & 50 & 5 \\
\hline \#08 & 16000 & 3000 & 64 & 50 & 5 \\
\hline \#09 & 16000 & 3500 & 64 & 50 & 5 \\
\hline
\end{tabular}

Table 3. Input parameters for different numerical simulation

In the case study analyzed, the ratio ' $\mathrm{h} / \mathrm{d}$ ' is also evaluated. The previous illustrated condition (see Section 2), in order to simplify Expression (6) into Inequality (7), can be rewritten as:

$$
\frac{d}{b} \gg \frac{s_{t}}{s_{l}}
$$

The ratios between the translation speed and the lifting speed are equal to 13 and to 12 , for the LPG forklift and for the electric forklift, respectively; therefore, the more stringent condition is set by the value 
13. Considering that, at most, stockpiles are constituted by 5 stacked units (see Table 3 ) and considering the item height, the average lift height of the process is around $1[\mathrm{~m}]$. In order to satisfy condition (6), the average cycle travelled distance has to be much greater than 13 [m]. This condition is respected since the distance travelled from $\mathrm{A}_{\mathrm{LU}}$ to $\mathrm{SA}$ is yet $20[\mathrm{~m}]$ and distances travelled inside the $\mathrm{SA}$ have to be added to it, when considering the average cycle travel. Consequently, the lift time can be neglected. As above mentioned, the travel speed of the forklift depends on the weight of the load carried up. In the simulation software, the variation of the transfer speed with the load carried up by the forklift is considered by means of the following relation:

$$
\frac{s_{t}}{s_{t \mathrm{MAX}}}=k=f(U)
$$

The characteristic ratio ' $k$ ' is a function of the forklift utilization. High values of the forklift utilization imply low values of ' $k$ ', since the speed must be reduced for technical and safety problems. Oppositely, low values of the forklift utilization imply high values of ' $k$ '. Consistently, the enviromental preference condition (7) can be customized as in equation (10).

$$
\frac{E H R_{F U E L}}{E H R_{E L}}>\frac{s_{t \text { FUEL } M A X}}{s_{t E L ~ M A X}} \frac{k_{F U E L}\left(U_{F U E L}\right)}{k_{E L}\left(U_{E L}\right)} \frac{\left\lceil\frac{Q \cdot W}{U_{E L} \cdot L C_{E L}}\right\rceil}{\left\lceil\frac{\mathcal{Q} \cdot W}{U_{F U E L} \cdot L C_{F U E L}}\right\rceil}
$$

It can be assumed a variation of the value $\mathrm{k}$ in the following range according to the utilization value.

$$
\text { for }\left\{\begin{array}{cc}
0 \leq U \leq 0.25: & 0.9 \leq k \leq 1 \\
0.25<U \leq 0.5: & 0.6 \leq k<0.9 \\
0.5<U \leq 0.75: & 0.4 \leq k<0.6 \\
0.75<U \leq 1: & 0.2 \leq k<0.4
\end{array}\right.
$$

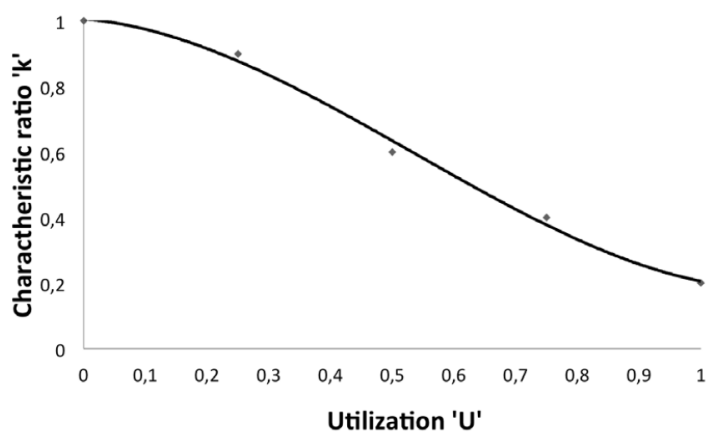

Figure 2. correlation between translation speed and forklift utilization in the simulation model 


\section{Results}

In the following, main results obtained are discussed. For each case, results and corresponding trends are depicted in Figure 2.

For the storage capacity Q = 1500 items (Figure 3a), the electric forklift performs better for "light" and "medium" weight $(\mathrm{W} \leq 3000[\mathrm{~kg}])$. On the contrary, the LPG forklift performs better than the electric ones for "heavy" (W>3000 [kg]) loads. This is due to the different forklifts load capacity. Indeed, the load capacity strongly affects the BS and forklift the utilization. In turn, the latter influences the speed employed and consequently the time required for the process.

In Figure 3b, results obtained in the case of items with a 'low' weight (equal to 2000 [kg]) are depicted. Coherently, the electric forklift has a lower CF than the LPG one. Considering a weight equal to 2000 [kg], the utilizations of the two forklift are the same and equal to 1. Unitary utilization means transit speed considerably lower than the maximum speed. Specifically, the translation speed of the electric forklift is lower than that of the LPG forklift. Consistently, the electric forklift time is higher. However, the time increase is compensated by the lower value of EHR, since the EHR is equal to $4.84\left[\mathrm{kgCO}_{2} / \mathrm{h}\right]$ for the electric forklift and $19.6\left[\mathrm{kgCO}_{2} / \mathrm{h}\right]$ for the LPG forklift (Table 1).

(a)

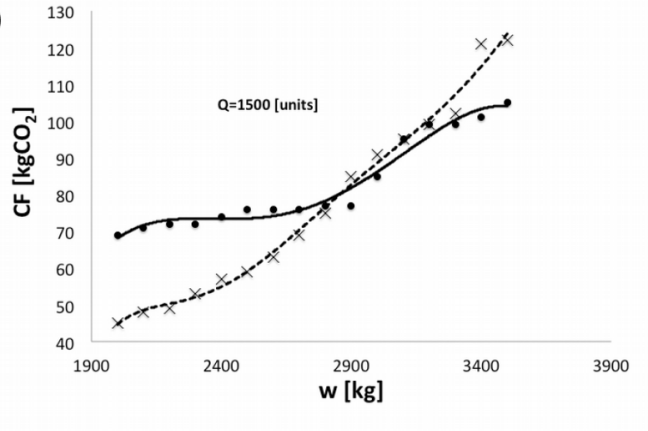

(b)

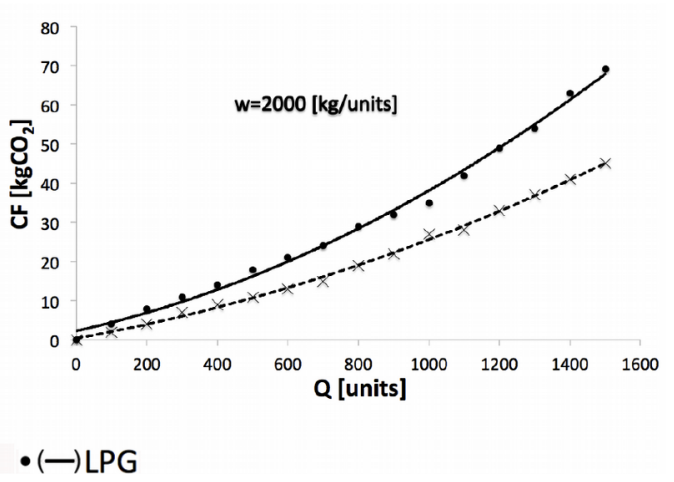

Figure 3. (a) CF vs. Weight value of items in case of 1500 units; (b) CF vs. Q values in case of item Weight equal to $2000[\mathrm{~kg}]$

In the simulation tests carried out, the following main conclusions are obtained:

- The electric powered forklift allows better performance (lower CF) than the LPG powered forklift for low-mid weight of the units (see figure 3);

- $\mathrm{CF}$ is almost the same for higher values of $\mathrm{Q}$ (greater warehouse capacity). 


\section{Conclusion}

In order to give a contribution to the disagreement between environmental performance of forklifts equipped with electric or LPG engines, in this paper a tool has been developed in order to identify the best MHE minimizing the carbon foot-print of inbound logistic activities. The equipment ensuring the minimal environmental impact has to be evaluated for each case. However, to a first approximation, as a general result, electric forklifts have to be considered preferable for low-mid weight units.

The developed model can be considered a valid support for decision makers.

Further research will be carried out in order to consider different sizes of the items to be stored, to include additional operational and design parameters (e.g. inventory turnover index, picking priority rules different layouts such as fishbone, transversal, etc.) as well as load/unload/transport times. The aim is enabling the model for the application to more complex scenarios, thus ensuring greater flexibility and increasing the number of industrial case studies to which it could be applied.

\section{References}

Amjed, T.W., \& Harrison, N.J. (2013). A Model for sustainable warehousing: from theory to best practices. Proceedings of the International Decision Sciences Institute and Asia Pacific DSI Conference. Paper presented at DSI: Bali, Indonesia. http://gebrc.nccu.edu.tw/proceedings/APDSI/2013/ (Accessed: November 2015).

ANSI (2012). Safety Standard for low lift and high lift trucks. ANSI/ITSDF B56.1-2012.

Boenzi, F., Digiesi, S., Facchini, F., \& Mummolo, G. (2015). Sustainable warehouse logistics: A NIP model for non-road vehicles and storage configuration selection. Proceedings of the XX Summer School Operational Excellence Experience "Francesco Turco". Paper presented: Naples, Italiy. http://summerschool-aidi.it/edition2015/images/Naples2015/proceed/29 facchini.pdf (Accessed: November 2015).

Chao-Hsien-Pan, J., Ming-Hun, W., \& Wen-Linag, C. (2014). A travel time estimation model for a high-level picker-to-part system with class-based storage policies. European Journal of Operational Research, 237, 1054-1066. https:/doi.org/10.1016/j.ejor.2014.02.037

Dey, A., LaGuardia, P., \& Srinivasan, M. (2011). Building sustainability in logistics operations: a research agenda. Management Research Review, 34(11), 1237-1259. https:/doi.org/10.1108/01409171111178774 
Digiesi, S., Mascolo, G., Mossa, G., \& Mummolo, G. (2016). New Models for Sustainable Logistics: Internalization of External Costs in Inventory Management. SpringerBriefs in Operations management. https:/doi.org/10.1007/978-3-319-19710-4_4

Eurostat (2015). Electricity production, consumption and market overview. European Commission Report.

Fichtinger, J., Ries, J.M., Grosse, E.H., \& Baker, P. (2015). Assessing the environmental impact of integrated inventory and warehouse management. Int. J. Production Economics, 170, 717-729. https:/doi.org/10.1016/j.ijpe.2015.06.025

Intergovernmental Panel on Climate Change (2006). Guidelines for national Greenhouse Gas Inventories. Edited by Eggleston, S., Buendia, L., Miwa, K., Ngara, T., \& Tanabe, K.

Johnson, E. (2008). Disagreement over carbon footprints: A comparison of electric and LPG forklifts. Energy Policy, 36(4), 1569-1573. https:/doi.org/10.1016/j.enpol.2008.01.014

Olivier, J.G.J, \& Muntean, M. (2015). Trends in global $\mathrm{CO}_{2}$ emissions. PBL and JRC.

Toyota (2002). Environmental Report. Toyota Industries Corporation.

Journal of Industrial Engineering and Management, 2016 (www.jiem.org)

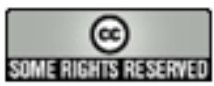

Article's contents are provided on an Attribution-Non Commercial 3.0 Creative commons license. Readers are allowed to copy, distribute and communicate article's contents, provided the author's and Journal of Industrial Engineering and Management's names are included. It must not be used for commercial purposes. To see the complete license contents, please visit http://creativecommons.org/licenses/by-nc/3.0/. 